\title{
Optimization of autohydrolysis conditions to extract antioxidant phenolic compounds from spent coffee grounds
}

\author{
Lina F. Ballesteros ${ }^{a}$, Mónica J. Ramirez ${ }^{\text {b }}$, Carlos E. Orrego ${ }^{\text {b }}$, José A. Teixeira ${ }^{\mathrm{a}}$, \\ Solange I. Mussatto ${ }^{c, *}$ \\ ${ }^{a}$ Centre of Biological Engineering, University of Minho, Campus Gualtar, 4710-057, Braga, Portugal \\ ${ }^{\mathrm{b}}$ Instituto de Biotecnología y Agroindustria, Universidad Nacional de Colombia sede Manizales, Km 7 via al Magdalena, Campus La Nubia, Manizales, \\ Colombia \\ ${ }^{c}$ Novo Nordisk Foundation Center for Biosustainability, Technical University of Denmark, Kemitorvet, Building 220, 2800, Kongens Lyngby, Denmark
}

\section{A R T I C L E I N F O}

\section{Article history:}

Received 21 June 2016

Received in revised form

6 November 2016

Accepted 19 November 2016

Available online 21 November 2016

\section{Keywords:}

Autohydrolysis

Spent coffee grounds

Phenolic compounds

Antioxidant activity

Extraction yield

\begin{abstract}
A B S T R A C T
Autohydrolysis, which is an eco-friendly technology that employs only water as extraction solvent, was used to extract antioxidant phenolic compounds from spent coffee grounds (SCG). Experimental assays were carried out using different temperatures $\left(160-200{ }^{\circ} \mathrm{C}\right)$, liquid/solid ratios $(5-15 \mathrm{ml} / \mathrm{g} \mathrm{SCG})$ and extraction times $(10-50 \mathrm{~min})$ in order to determine the conditions that maximize the extraction results. The optimum conditions to produce extracts with high content of phenolic compounds (40.36 mg GAE/ g SCG) and high antioxidant activity (FRAP $=69.50 \mathrm{mg} \mathrm{Fe}(\mathrm{II}) / \mathrm{g} \mathrm{SCG}$, DPPH $=28.15 \mathrm{mg} \mathrm{TE} / \mathrm{g} \mathrm{SCG}$, ABTS $=31.46 \mathrm{mg}$ TE $/ \mathrm{g} \mathrm{SCG}$, and TAA $=66.21 \mathrm{mg} \alpha-\mathrm{TOC} / \mathrm{g} \mathrm{SCG}$ ) consisted in using $15 \mathrm{ml}$ water $/ \mathrm{g}$ SCG, at $200{ }^{\circ} \mathrm{C}$ during $50 \mathrm{~min}$. Apart from being a green technology, autohydrolysis under optimized conditions was demonstrated to be an efficient method to extract antioxidant phenolic compounds from SCG.
\end{abstract}

(c) 2016 Elsevier Ltd. All rights reserved.

\section{Introduction}

Agro-industrial residues often contain high added-value substances that can be extracted by designing a proper bioprocess and exploited in the food, chemical, cosmetic and pharmaceutical industries. Spent coffee grounds (SCG), for instance, is the main waste of the coffee industry, obtained during the processing of roasted coffee powder with hot water or steam to prepare instant coffee. This residue is generated in large quantities around the world (approx. 6,000,000 tons/year) (Mussatto et al., 2011a) and, even though some researches have revealed functional potential of different compounds found in SCG such as polysaccharides, proteins, phenolic compounds, minerals, among others, this residue still has not been used as raw material in industrial processes.

Nowadays, phenolic compounds (PC) have attracted great interest due to their enormous benefits for human health. Some researches have shown that the potential of PC is related to their antioxidant activity, protecting against chronic-degenerative

\footnotetext{
* Corresponding author.

E-mail addresses: smussatto@biosustain.dtu.dk, solangemussatto@hotmail.com (S.I. Mussatto).
}

diseases such as cancer, cardiovascular diseases, neurodegenerative diseases and diabetes mellitus (Jiménez et al., 2008; Martins et al., 2011; Mussatto, 2015; Prasad et al., 2011). However, their properties are not limited to the antioxidant activity, but they can also present antiallergenic, antimicrobial and/or anti-inflammatory effects (Farah and Donangelo, 2006; Martins et al., 2011; Mussatto, 2015). Additionally, PC improve the organoleptic properties of vegetable origin food, and can also be used as raw material in the development of functional food or as natural preservatives against food degradation (Ballesteros et al., 2014b; Rodríguez-Meizoso et al., 2010).

A great variety of techniques can be used for recovering antioxidant PC from agro-industrial residues and natural resources, including solid-liquid extraction using organic solvents, autohydrolysis, ultrasound-assisted extraction, microwave-assisted extraction, among others (Ballesteros et al., 2014b; Cortazar et al., 2005; Markom et al., 2007; Mussatto, 2015). Recently, SCG have been studied as a natural source of PC (Murthy and Naidu, 2012; Mussatto et al., 2011b; Panusa et al., 2013; Zuorro and Lavecchia, 2012), and the ability of a conventional solid-liquid extraction method to recover PC from SCG using organic solvents such as ethanol (Panusa et al., 2013; Zuorro and Lavecchia, 2012), methanol 
(Mussatto et al., 2011b) and isopropanol (Murthy and Naidu, 2012) has also been demonstrated. However, there is a necessity of evaluating and identifying more eco-friendly methodologies that do not require the use of organic solvents and may enhance the extracts compatibility for the food industry and enable their use as added-value constituent for different applications. Among these techniques, autohydrolysis could be an interesting alternative for the recovery of antioxidant PC from SCG since it does not require organic solvents for the reaction, but only water, being able to generate a slightly acidic media due to the partial cleavage of acetyl groups existing in the material structure (Conde and Mussatto, 2016; Nabarlatz et al., 2007). Additionally, autohydrolysis process offers several advantages such as elimination of corrosive problems in the equipment due to mild $\mathrm{pH}$ of reaction media, reduction of operational costs since no further neutralization is needed, and mild operational conditions for selective degradation of the biomass (Carvalheiro et al., 2004; Conde and Mussatto, 2016).

In a previous study, autohydrolysis under mild reaction conditions was demonstrated to be a technology with great potential to recover PC from SCG (Conde and Mussatto, 2016). However, the conditions that maximize the extraction of these compounds from SCG were not established yet, and it is well-know that the efficiency of this extraction process is affected by the variables used for reaction, such as the solvent/solid ratio, time, temperature, particle size of the solid matrix, among others. Thus, it is very important to optimize the extraction conditions in order to maximize the extraction efficiency. Optimizing the process conditions is also important because allows a more suitable and complete exploitation of the feedstock, saving time, manpower, and making the process less expensive, reliable, cleaner and attractive to be implemented at industrial scale. Taking these facts into account, the aim of the present study was to optimize the process conditions to extract antioxidant PC from SCG by using the eco-friendly technique of autohydrolysis. Extractions were performed using different temperatures, liquid/solid ratios and reaction times and the effects of these operational variables on the extraction results were verified. Finally, the conditions able to produce a phenolic rich extract with high antioxidant activity were determined.

\section{Materials and methods}

\subsection{Raw material and chemicals}

Spent coffee grounds (SCG), which were derived from mixtures of Arabica and Robusta coffee varieties imported from different countries including Brazil, Colombia, Timor and Angola, among others, were supplied by the Portuguese coffee industry NovaDeltaComércio e Indústria de Cafés S.A. (Campo Maior, Portugal). The material was dried in an oven at $60{ }^{\circ} \mathrm{C}$ until $5 \%$ moisture content and stored for further extractions.

All the chemicals used were analytical grade, purchased from Sigma-Aldrich (Chemie GmbH, Steinheim, Germany), Panreac Química (Barcelona, Spain) and Fisher Scientific (Leicestershire, UK). Ultrapure water from a Milli-Q System (Millipore Inc., USA) was used.

\subsection{Autohydrolysis process}

Autohydrolysis assays were performed under different conditions of temperature $\left(160-200{ }^{\circ} \mathrm{C}\right)$, liquid/solid ratio (5-15 ml water/ g SCG) and extraction time (10-50 min), which were combined according to a $2^{3}$ central composite design. For the reactions, ultrapure water and SCG were added into $160 \mathrm{ml}$ cylindrical stainless steel reactors (Parr Instruments Company, Illinois, USA), which were duly closed and placed into an oil-bath with open heating circulator and temperature control (Julabo, Labortechnik GmbH, Seelbach, Germany). The reactors were maintained in the bath at the desired temperature, during the time required for each reaction. Then, they were removed and immediately cooled down in an icebath during $10 \mathrm{~min}$ to stop the reaction. The total content of each reactor was centrifuged $(2500 \mathrm{~g}, 20 \mathrm{~min}$ ) and the supernatant (SCG extract) was filtered through $0.22 \mu \mathrm{m}$ filters and stored at $-20{ }^{\circ} \mathrm{C}$ until further analyses. The volume of extract recovered after each extraction was quantified and used to calculate the extraction yield, which was expressed as g recovered extract per $100 \mathrm{~g} \mathrm{SCG}$.

\subsection{Analytical methodology}

\subsubsection{Phenolic compounds}

The total content of phenolic compounds (PC) in SCG extracts was estimated by using the Folin-Ciocalteu reagent method adapted to a 96-well microplate, as previously described (Ballesteros et al., 2014a). The total content of PC was expressed as milligram of gallic acid equivalent per $\mathrm{g}$ of dry weight material (mg GAE/g SCG).

\subsubsection{Antioxidant activity}

The antioxidant activity of SCG extracts was determined by four different methods, namely the ferric reducing antioxidant power (FRAP) assay, DPPH radical scavenging activity assay, the radical cation decolorization (ABTS) assay, and total antioxidant activity (TAA), assay, as described by Ballesteros et al. (2015, 2014a). FRAP values were expressed as $\mathrm{mg}$ of ferrous equivalent per $\mathrm{g}$ of dry weight material (mg Fe (II)/g SCG). DPPH and ABTS data were plotted as a function of antioxidant concentration to obtain DPPH and $\mathrm{ABTS}$ inhibition concentration at $50 \%\left(\mathrm{IC}_{50}\right)$. The $\mathrm{IC}_{50}$ values were expressed as $\mathrm{mg}$ of Trolox equivalent per $\mathrm{g}$ of dry weight material (mg TE/g SCG). TAA was expressed as milligrams of $\alpha$ tocopherol equivalent per $\mathrm{g}$ of dry weight material ( $\mathrm{mg} \mathrm{TOC} / \mathrm{g} \mathrm{SCG}$ ).

\subsubsection{Flavonoids}

The total content of flavonoids in SCG extracts was estimated by colorimetric assay as previously described (Ballesteros et al., 2014a), being the results expressed as milligram quercetin equivalent per dry weight material (mg QE/g SCG).

\subsubsection{Determination of other compounds in SCG extracts}

Chlorogenic acid, furfural and hydroxymethylfurfural were analyzed by high performance liquid chromatography (HPLC) (Mussatto et al., 2011b). The concentration of these components was determined from standard curves made with known concentrations of each compound. The response of the UV detector was recorded and integrated using the D-7000 HPLC System Manager software (Hitachi).

\subsection{Statistical analysis}

The influence of the variables temperature, liquid/solid ratio and extraction time on the recovery of antioxidant PC by autohydrolysis of SCG was investigated through a $2^{3}$ central composite design. The real and coded values of the variables used in the experimental design are given in Table 1 . Statistical significance of the variables was determined at $5 \%$ probability level $(p<0.05)$. The data obtained from the design were fitted to second order polynomial equations, and the models were simplified by elimination of statistically insignificant terms. Statistical significance of the regression coefficients was determined by Student's $t$-test, and the proportion of variance explained by the models were given by the multiple coefficient of determination, $\mathrm{R}^{2}$. Statistical analysis of the data and the determination of the conditions able to maximize the extraction 
Table 1

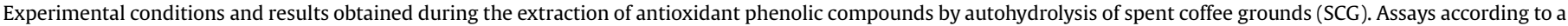
$2^{3}$ central composite design.

\begin{tabular}{|c|c|c|c|c|c|c|c|c|c|}
\hline \multirow[t]{2}{*}{ Assay } & \multicolumn{3}{|l|}{ Variables $^{\mathrm{a}}$} & \multicolumn{6}{|l|}{ Responses $^{\mathrm{b}}$} \\
\hline & $\mathrm{X}_{1}$ & $\mathrm{X}_{2}$ & $\mathrm{X}_{3}$ & PC & FRAP & $\mathrm{DPPH}$ & ABTS & TAA & Yield \\
\hline 1 & $160(-1)$ & $5(-1)$ & $10(-1)$ & $6.09 \pm 0.07$ & $8.34 \pm 0.28$ & $4.58 \pm 0.02$ & $5.39 \pm 0.46$ & $8.14 \pm 0.23$ & 3.00 \\
\hline 2 & $200(+1)$ & $5(-1)$ & $10(-1)$ & $8.59 \pm 0.09$ & $13.90 \pm 0.56$ & $8.27 \pm 0.02$ & $8.03 \pm 0.01$ & $12.61 \pm 0.27$ & 6.15 \\
\hline 3 & $160(-1)$ & $5(-1)$ & $50(+1)$ & $8.59 \pm 0.14$ & $16.68 \pm 1.11$ & $8.84 \pm 0.18$ & $8.72 \pm 0.04$ & $14.15 \pm 0.23$ & 7.09 \\
\hline 4 & $200(+1)$ & $5(-1)$ & $50(+1)$ & $10.95 \pm 0.24$ & $22.24 \pm 1.67$ & $10.01 \pm 0.05$ & $10.36 \pm 0.16$ & $20.94 \pm 0.08$ & 10.91 \\
\hline 5 & $160(-1)$ & $15(+1)$ & $10(-1)$ & $12.63 \pm 0.27$ & $27.80 \pm 1.11$ & $13.95 \pm 0.13$ & $13.00 \pm 0.15$ & $26.06 \pm 0.26$ & 8.22 \\
\hline 6 & $200(+1)$ & $15(+1)$ & $10(-1)$ & $19.55 \pm 0.77$ & $41.70 \pm 1.67$ & $19.63 \pm 0.01$ & $21.46 \pm 0.07$ & $37.38 \pm 1.38$ & 11.98 \\
\hline 7 & $160(-1)$ & $15(+1)$ & $50(+1)$ & $17.39 \pm 0.30$ & $44.48 \pm 2.50$ & $24.07 \pm 1.74$ & $22.17 \pm 0.12$ & $39.30 \pm 1.38$ & 14.66 \\
\hline 8 & $200(+1)$ & $15(+1)$ & $50(+1)$ & $39.29 \pm 0.83$ & $69.50 \pm 2.22$ & $29.57 \pm 0.07$ & $31.13 \pm 0.80$ & $64.79 \pm 0.98$ & 26.06 \\
\hline 9 & $160(-1)$ & $10(0)$ & $30(0)$ & $23.57 \pm 0.47$ & $36.14 \pm 1.39$ & $15.95 \pm 0.11$ & $15.39 \pm 0.20$ & $25.63 \pm 0.42$ & 10.51 \\
\hline 10 & $200(+1)$ & $10(0)$ & $30(0)$ & $28.26 \pm 0.23$ & $52.82 \pm 3.89$ & $21.08 \pm 0.09$ & $14.27 \pm 0.05$ & $40.29 \pm 0.55$ & 21.31 \\
\hline 11 & $180(0)$ & $10(0)$ & $10(-1)$ & $21.42 \pm 0.47$ & $33.36 \pm 1.95$ & $15.19 \pm 0.09$ & $17.61 \pm 0.15$ & $22.95 \pm 0.18$ & 8.32 \\
\hline 12 & $180(0)$ & $10(0)$ & $50(+1)$ & $27.57 \pm 0.32$ & $50.04 \pm 1.67$ & $23.52 \pm 0.22$ & $23.25 \pm 0.01$ & $37.58 \pm 1.85$ & 20.16 \\
\hline 13 & $180(0)$ & $5(-1)$ & $30(0)$ & $10.62 \pm 0.07$ & $19.46 \pm 0.56$ & $10.25 \pm 0.05$ & $8.66 \pm 0.09$ & $17.08 \pm 0.04$ & 8.82 \\
\hline 14 & $180(0)$ & $15(+1)$ & $30(0)$ & $36.88 \pm 0.51$ & $55.60 \pm 0.56$ & $29.79 \pm 0.40$ & $27.03 \pm 0.11$ & $45.48 \pm 0.36$ & 19.45 \\
\hline 15 & $180(0)$ & $10(0)$ & $30(0)$ & $21.52 \pm 0.50$ & $38.92 \pm 0.83$ & $20.05 \pm 1.66$ & $17.61 \pm 0.15$ & $29.80 \pm 0.20$ & 11.90 \\
\hline 16 & $180(0)$ & $10(0)$ & $30(0)$ & $21.40 \pm 0.52$ & $36.14 \pm 1.39$ & $19.60 \pm 0.08$ & $17.47 \pm 0.04$ & $28.72 \pm 0.96$ & 13.03 \\
\hline 17 & $180(0)$ & $10(0)$ & $30(0)$ & $23.21 \pm 0.29$ & $38.92 \pm 0.83$ & $19.79 \pm 0.29$ & $18.38 \pm 0.27$ & $31.33 \pm 0.88$ & 14.11 \\
\hline 18 & $180(0)$ & $10(0)$ & $30(0)$ & $25.10 \pm 0.65$ & $38.92 \pm 1.67$ & $19.96 \pm 0.10$ & $18.24 \pm 0.25$ & $29.12 \pm 0.48$ & 14.47 \\
\hline 19 & $180(0)$ & $10(0)$ & $30(0)$ & $23.77 \pm 0.13$ & $36.14 \pm 0.28$ & $20.43 \pm 0.34$ & $21.19 \pm 0.22$ & $33.99 \pm 1.14$ & 13.78 \\
\hline 20 & $180(0)$ & $10(0)$ & $30(0)$ & $25.95 \pm 0.18$ & $38.92 \pm 0.83$ & $19.79 \pm 0.21$ & $21.51 \pm 0.17$ & $32.46 \pm 0.84$ & 14.26 \\
\hline
\end{tabular}

a $\mathrm{X}_{1}$ : temperature $\left({ }^{\circ} \mathrm{C}\right) ; \mathrm{X}_{2}$ : liquid/solid ratio $(\mathrm{ml} / \mathrm{g}) ; \mathrm{X}_{3}$ : extraction time (min). Real and (coded) values.

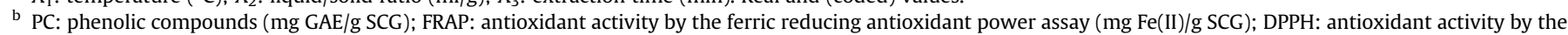

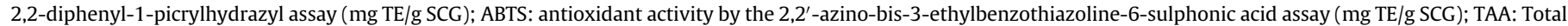
antioxidant activity ( $\mathrm{mg} \alpha$-TOC/g SCG); Yield: (\% (w/w)).

results were performed using the softwares Statistica (version 8.0), and Design expert (version 8.0).

\section{Results and discussion}

The process variables used for extraction reactions, such as the reaction time, temperature and liquid/solid ratio, usually have great influence both on the kinetics of PC release from the solid matrix as well as on the antioxidant activity of the produced extracts. Therefore, this study aimed to evaluate the effect of these three variables on the recovery of PC with high antioxidant activity by autohydrolysis of SCG, with the objective of selecting the conditions that maximize the extraction results. The experimental conditions used in each assay and the respective results of PC, FRAP, DPPH, ABTS and TAA are presented in Table 1 . As can be seen, in the range of values studied in this work, the process variables exerted great influence on the evaluated responses. The worst values for all the responses were achieved when using the lowest limit of each variable, while the best results were obtained when using the highest limit (except for the DPPH assay). For the results of antioxidant activity, in particular, some differences among the results were observed for the different assays, which can be explained by the fact that the methods differ from each other in terms of reaction mechanisms, oxidant and target/probe species, and reaction conditions (Conde and Mussatto, 2016; Karadag et al., 2009).

The greatest content of PC (39.29 $\pm 0.83 \mathrm{mg}$ GAE/g SCG) obtained in the present study by autohydrolysis of SCG, was higher than those reported in the literature for the recovery of PC from SCG by using organic solvents such as ethanol (28.26 mg GAE/g SCG, using ethanol 60\%, $50 \mathrm{ml} / \mathrm{g} \mathrm{SCG}, 60^{\circ} \mathrm{C}, 30 \mathrm{~min}$ ) (Panusa et al., 2013) and methanol (16 mg GAE/g SCG, using methanol 60\%, $40 \mathrm{ml} / \mathrm{g} \mathrm{SCG}$, $60-65{ }^{\circ} \mathrm{C}, 90 \mathrm{~min}$ ) (Mussatto et al., 2011b), or by using autohydrolysis under mild process conditions (32.92 mg GAE/g SCG, using $20 \mathrm{ml}$ water/g SCG, $120^{\circ} \mathrm{C}, 20 \mathrm{~min}$ ) (Conde and Mussatto, 2016). This value was also higher when compared to those reported for autohydrolysis of other natural sources such as corncobs (23.9 mg GAE/g dry matter), eucalypt wood (19.2 mg GAE/g dry matter), almond shells (36.2 mg GAE/g dry matter) and grape pomace (21.6 mg GAE/g dry matter) (Conde et al., 2011).

The antioxidant activity of SCG extracts was also higher than the values reported to other antioxidant sources including medicinal plants like Sophora japonica (4.63 mg TE/g dry matter), Terminalia chebula (13.81 mg TE/g dry matter), Prunella vulgaris (2.62 mg TE/ $\mathrm{g}$ dry matter), and Scutellaria barbata (1.27 mg TE/g dry matter), when aqueous extracts were evaluated by the ABTS assay (Cai et al., 2004), and fruits and grains such as black chokeberry, peach, apricot, hulled buckwheat, oat flakes when assessed by DPPH and FRAP methods (Stratil et al., 2007). These results confirm that SCG is a phenolic rich agro-industrial waste with important antioxidant potential, and autohydrolysis is an efficient technique to extract such compounds from SCG.

Some researchers have related the potential of PC with their antioxidant activity (Alothman et al., 2009; Ballesteros et al., 2014b; Cai et al., 2004; Mussatto, 2015). However, usually the correlation

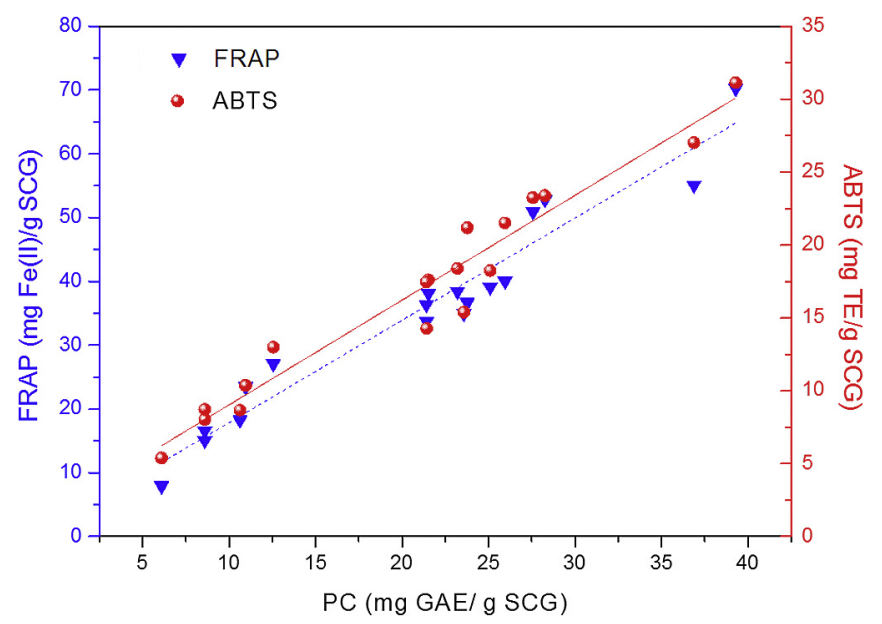

Fig. 1. Correlation analysis chart for the responses total phenolic compounds (PC) and antioxidant activity (FRAP and ABTS assays - coefficients $\mathrm{R}^{2}=0.94$ and 0.95 , respectively) of extracts obtained by autohydrolysis of spent coffee grounds. 
a)

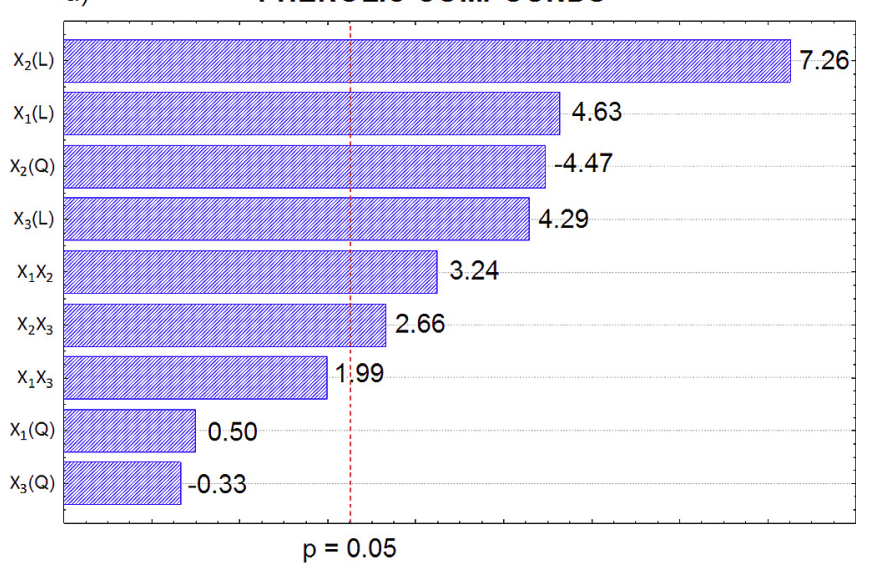

c)

Standardized Effect Estimate (Absolute Value)
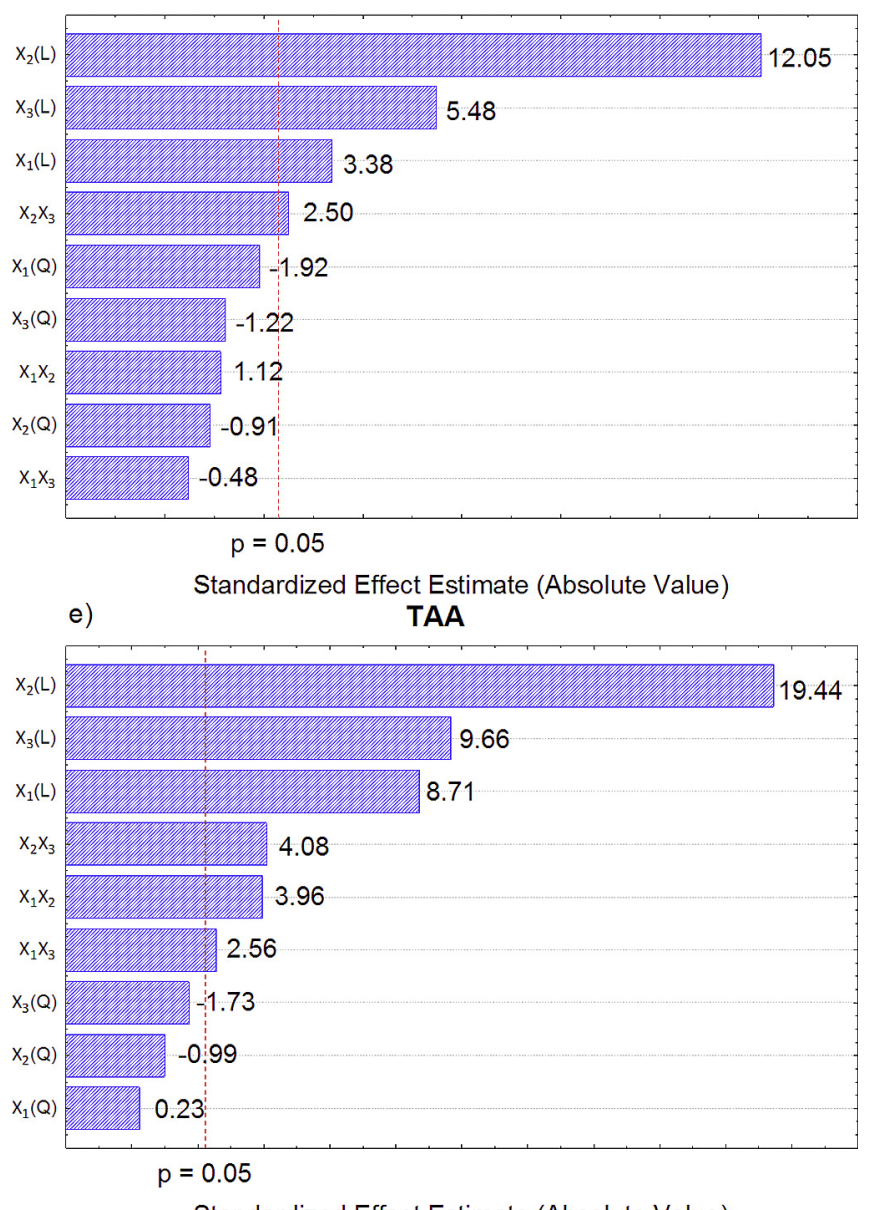

Standardized Effect Estimate (Absolute Value) b)

FRAP

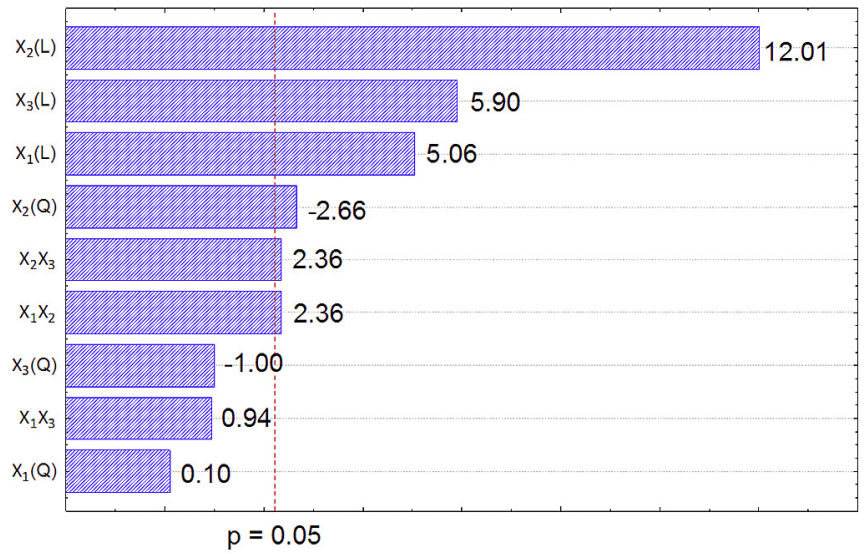

Standardized Effect Estimate (Absolute Value)

d) ABTS
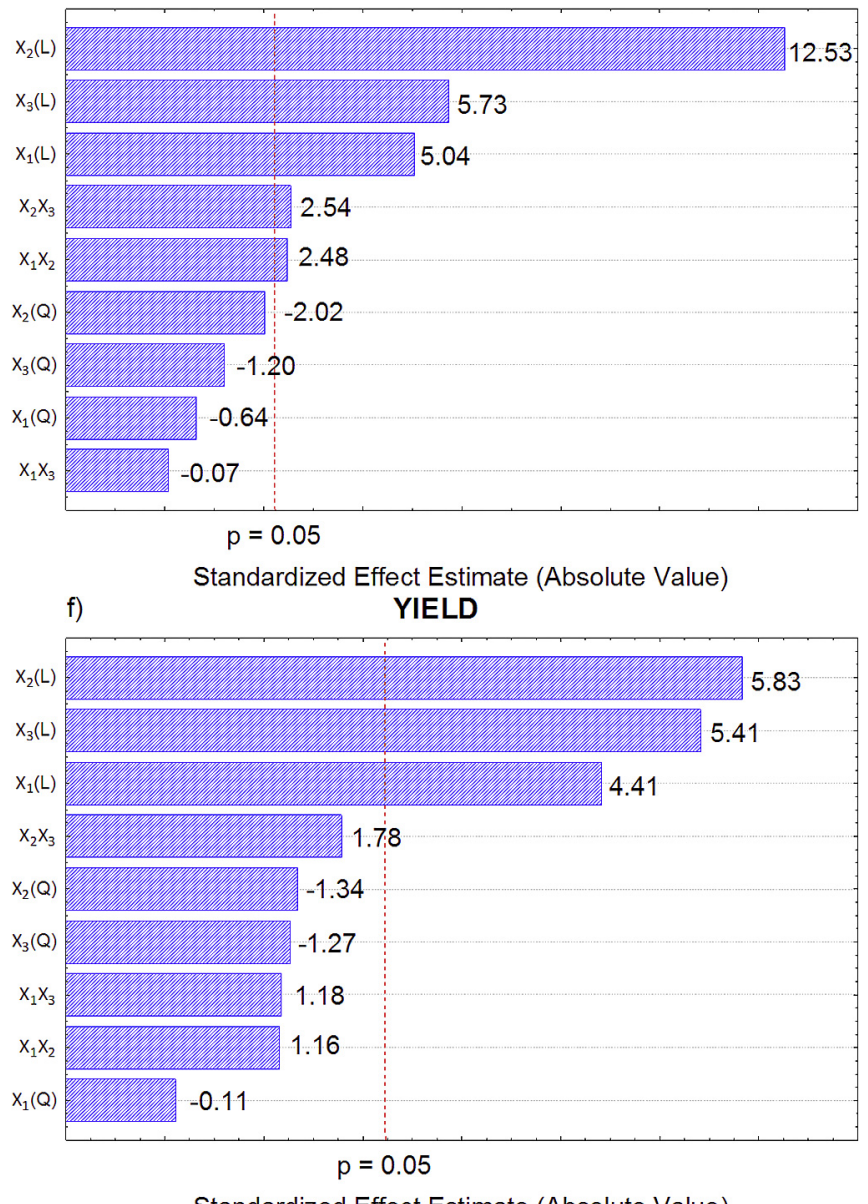

Standardized Effect Estimate (Absolute Value)

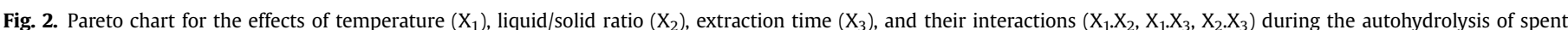

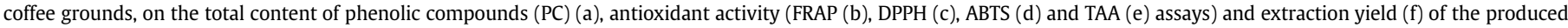
extracts. $\mathrm{L}$ and $\mathrm{Q}$ correspond to the effects at linear and quadratic levels, respectively.

cannot be evidenced for all the antioxidant activity assays due to the fact that each method has different reaction mechanisms, as previously explained. In the present study, the relationship among total PC extracted by autohydrolysis of SCG and the results of antioxidant activity obtained by the different methods (which were based on different reaction mechanisms) was verified. A correlation analysis chart was plotted and revealed that the antioxidant activity by FRAP and ABTS assays was directly proportional to the content of PC present in the SCG extracts, the data being correlated with coefficients $\mathrm{R}^{2}=0.94$ for FRAP assay and $\mathrm{R}^{2}=0.95$ ABTS assay (Fig. 1). These results suggest that the PC present in SCG extracts contributed significantly to the antioxidant activity of the extracts when evaluated by both FRAP and ABTS assays.

In order to verify the effect of each process variable used for the 
Table 2

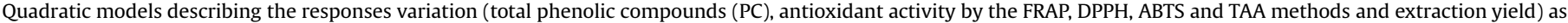
function of the process variables (temperature, liquid/solid ratio and extraction time) and their correspondent $\mathrm{R}^{2}$ coefficients.

\begin{tabular}{|c|c|c|}
\hline Response & Model equation $^{\mathrm{a}}$ & $\mathrm{R}^{2}$ \\
\hline PC (mg GAE/g SCG) & $\mathrm{PC}=24.18+3.84 \mathrm{X}_{1}+6.61 \mathrm{X}_{2}+3.56 \mathrm{X}_{3}+3.00 \mathrm{X}_{1} \mathrm{X}_{2}+2.46 \mathrm{X}_{2} \mathrm{X}_{3}-8.59 \mathrm{X}_{2}^{2}$ & 0.93 \\
\hline FRAP (mg Fe(II)/g SCG) & $\mathrm{FRAP}=40.03+6.67 \mathrm{X}_{1}+15.85 \mathrm{X}_{2}+7.78 \mathrm{X}_{3}+3.48 \mathrm{X}_{1} \mathrm{X}_{2}+3.48 \mathrm{X}_{2} \mathrm{X}_{3}-8.06 \mathrm{X}_{2}^{2}$ & 0.96 \\
\hline DPPH (mg TE/g SCG) & $\mathrm{DPPH}=19.77+2.12 \mathrm{X}_{1}+7.51 \mathrm{X}_{2}+3.44 \mathrm{X}_{3}+1.76 \mathrm{X}_{2} \mathrm{X}_{3}-4.17 \mathrm{X}_{1}^{2}$ & 0.94 \\
\hline ABTS (mg TE/g SCG) & $\mathrm{ABTS}=18.49+2.06 \mathrm{X}_{1}+7.36 \mathrm{X}_{2}+3.01 \mathrm{X}_{3}+1.64 \mathrm{X}_{1} \mathrm{X}_{2}+1.65 \mathrm{X}_{2} \mathrm{X}_{3}-2.90 \mathrm{X}_{2}^{2}$ & 0.95 \\
\hline TAA (mg $\alpha-$ TOC/g SCG) & $\mathrm{TAA}=31.39+6.27 \mathrm{X}_{1}+14.02 \mathrm{X}_{2}+6.96 \mathrm{X}_{3}+3.19 \mathrm{X}_{1} \mathrm{X}_{2}+2.06 \mathrm{X}_{1} \mathrm{X}_{3}+3.29 \mathrm{X}_{2} \mathrm{X}_{3}-3.00 \mathrm{X}_{3}^{2}$ & 0.98 \\
\hline Yield $(\%(w / w))$ & Yield $=-14.78+3.33 \mathrm{X}_{1}+4.40 \mathrm{X}_{2}+4.08 \mathrm{X}_{3}-3.11 \mathrm{X}_{2}^{2}$ & 0.84 \\
\hline
\end{tabular}

a $\mathrm{X}_{1}$ : temperature; $\mathrm{X}_{2}$ : liquid/solid ratio; $\mathrm{X}_{3}$ : extraction time. The equations are expressed in terms of coded values $(-1,0,+1)$.

autohydrolysis of SCG on the efficiency of the responses, Pareto charts were plotted (Fig. 2). In this figure, bars extending beyond the vertical line corresponded to the effects statistically significant at $95 \%$ confidence level. The length of each bar was proportional to the standardized effect. The statistical analysis revealed a significant effect $(p<0.05)$ of the three variables on the total PC extraction from SCG, being the liquid/solid ratio $\left(\mathrm{X}_{2}\right)$ the most significant variable, as shown in Fig. 2a. Similar trend was observed on the antioxidant activity responses (Fig. 2b, c, d, e) as well as on the extraction yield response (Fig. 2f). Although the temperature $\left(\mathrm{X}_{1}\right)$ had a significant effect $(p<0.05)$ on all the responses, it had more influence on PC extraction, being the second most important variable, after de liquid/solid ratio, affecting this response (Fig. 2a). On the other hand, the reaction time $\left(\mathrm{X}_{3}\right)$ had a more significant effect on the antioxidant activity and yield responses when compared to temperature (Fig. 2b, c, d, e, f). Similar to the present study, the solvent/solid ratio and temperature have been reported as two of the most significant variables affecting the extraction of antioxidant PC from SCG by conventional solid-liquid extraction using ethanol as solvent (Ballesteros et al., 2014a; Conde et al., 2011; Mussatto et al., 2011b; Zuorro and Lavecchia, 2012).

Not only the linear terms (L) of the variables, but also the quadratic terms $(\mathrm{Q})$ and interactions had statistical significance on the responses $(p<0.05)$, as shown in Fig. 2 . These results reveal that the value of the responses was linearly raised by increasing the value of the process variables but up to a certain limit, after which the values of the responses decreased. All the responses were then fitted to second-order polynomial equations, in order to describe the responses variations as a function of the variables in the range of values studied. The non-significant terms $(p>0.05)$ were disregarded in order to improve the fitting and prediction of the models. The equation obtained for each response as a function of the process variables (temperature, $\mathrm{X}_{1}$; liquid/solid ratio, $\mathrm{X}_{2}$; time, $\mathrm{X}_{3} ;-$ coded values) is shown in Table 2 . None of these models presented lack-of-fit and revealed high coefficient of determination $\mathrm{R}^{2}$, ranging from 0.84 to 0.98 , which means a close agreement between the experimental results and those predicted by the equations. These models can be efficiently employed for a rapid prediction of the extraction results to be achieved when using temperatures, liquid/solid ratios and extraction times in the range of values evaluated in this study.

Based on the established model equations, contour lines graphs for PC, antioxidant activity responses and extraction yield were plotted (Fig. 3). These graphs are presented at constant temperature of $200{ }^{\circ} \mathrm{C}$ (the highest value evaluated in the present study), since it resulted in the highest values for all responses, but temperature had the less significant effect for most of the responses when compared to the extraction time and liquid/solid ratio. This is in agreement with the findings reported by Dorta et al. (2012), who observed an enhanced diffusion rate and solubility of the compounds in the solvent when the temperature was increased, improving the extraction process. In fact, the polarity of water (dielectric constant) is decreased when the temperature is increased, due to the breakdown of hydrogen bonds when water is subjected to high temperatures, changing the water properties. Under these conditions, the water becomes less polar and acts like an organic solvent such as methanol or ethanol, increasing the solubility of the organic materials in it (Katritzky and Allin, 1996).

Fig. 3 shows the existence of a region where all the responses are maximized. The content of PC, for example (Fig. 3a), increased when the liquid/solid ratio was higher than $10 \mathrm{ml} / \mathrm{g}$, probably because more water could react with the SCG particles while more PC could permeate to the water (Prasad et al., 2009). The time also played a significant role in the PC extraction, as the recovery was maximized between 45 and 50 min of extraction time. It is worth mentioning that obtaining high content of PC in the extract is also beneficial for the later step of purification and impacts also on the economy of the process, since at high product concentration, lower capital cost and energy consumption are required for purification.

The results of antioxidant activity (Fig. 3b, c, d, e) and extraction yield (Fig. 3f) had a similar behavior when compared to the results of PC (Fig. 3a), i.e., all the responses were maximized when the liquid/solid ratio was higher than $12.5 \mathrm{ml} / \mathrm{g}$ and the extraction time was superior than $40 \mathrm{~min}$. Considering these results, a graphical optimization was carried out in order to determine the extraction conditions able to produce an extract containing maximum content of total PC as possible and high antioxidant activity as possible. The optimization process was performed by overlapping the curves obtained in the models to each response. To determine the optimal extraction conditions, the following criteria was adopted: PC $\geq 35 \mathrm{mg} \quad$ GAE $/ \mathrm{g} \quad$ SCG, $\quad$ FRAP $\geq 64 \mathrm{mg} \quad \mathrm{Fe}(\mathrm{II}) / \mathrm{g} \quad \mathrm{SCG}$, $\mathrm{DPPH} \geq 25 \mathrm{mg} \mathrm{TE} / \mathrm{g}$ SCG, ABTS $\geq 28 \mathrm{mg} \mathrm{TE} / \mathrm{g} \mathrm{SCG}$, and TAA $\geq 60 \mathrm{mg} \alpha$-TOC/g SCG. The overlaying plot attained (Fig. 4) revealed an area in which all these criteria are satisfied (shadow area) and the optimum point (within this area) where the results of the responses were maximized was then chosen, which corresponded to using $200{ }^{\circ} \mathrm{C}, 15 \mathrm{ml}$ water/g SCG and $50 \mathrm{~min}$. Under these conditions, the model predicts a PC extraction of 35.07 m GAE/SCG; and antioxidant activity values for FRAP, DPPH, ABTS and TAA of $69.50 \mathrm{mg}$ Fe(II)/g SCG, $30.47 \mathrm{mg}$ TE/g SCG, $32.54 \mathrm{mg}$ TE/g SCG and $64.17 \mathrm{mg} \alpha$-TOC/g SCG, respectively. The optimal point was later reproduced to validate the results, obtaining values within $5 \%$ of relative standard deviation (Table 3 ), which demonstrate a good degree of prediction.

The PC content obtained in the present study under the optimized autohydrolysis conditions (40.36 mg GAE/g SCG) was significantly higher than the values reported in other studies using conventional solid-liquid extraction to recover PC from SCG. The values were 4 -fold higher than those achieved by Murthy and Naidu (2012) using isopropanol 60\% as extraction solvent (10.20 mg GAE/g SCG), 2-fold higher when compared to the results reported by Mussatto et al. (2011b) and Zuorro and Lavecchia (2012) using methanol (16.00 mg GAE/g SCG) and ethanol (19.98 mg GAE/g SCG), respectively, and 1.4-fold higher than those 
a) PC (mg GAE/g SCG)

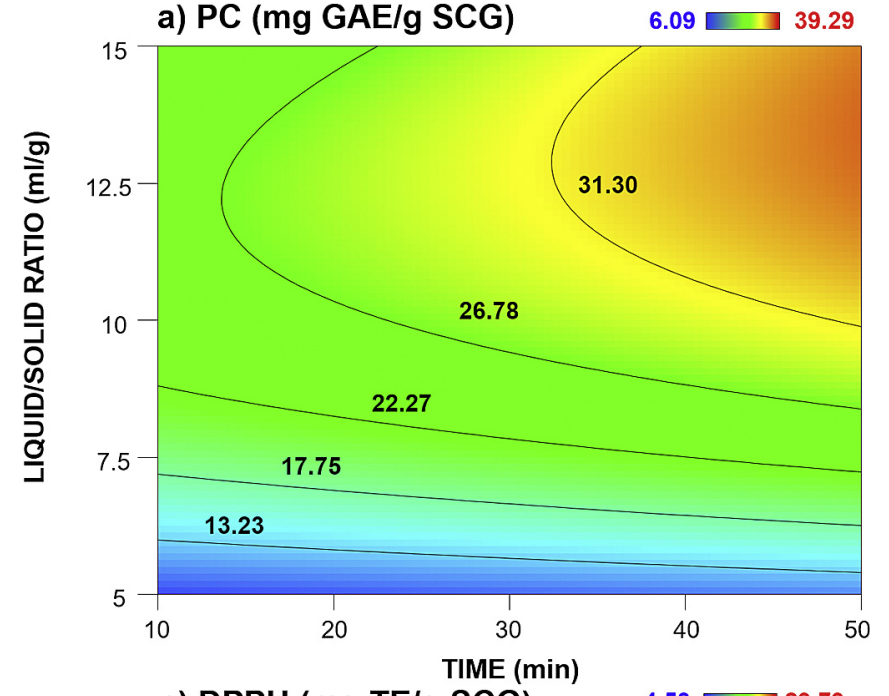

c) DPPH (mg TE/g SCG)

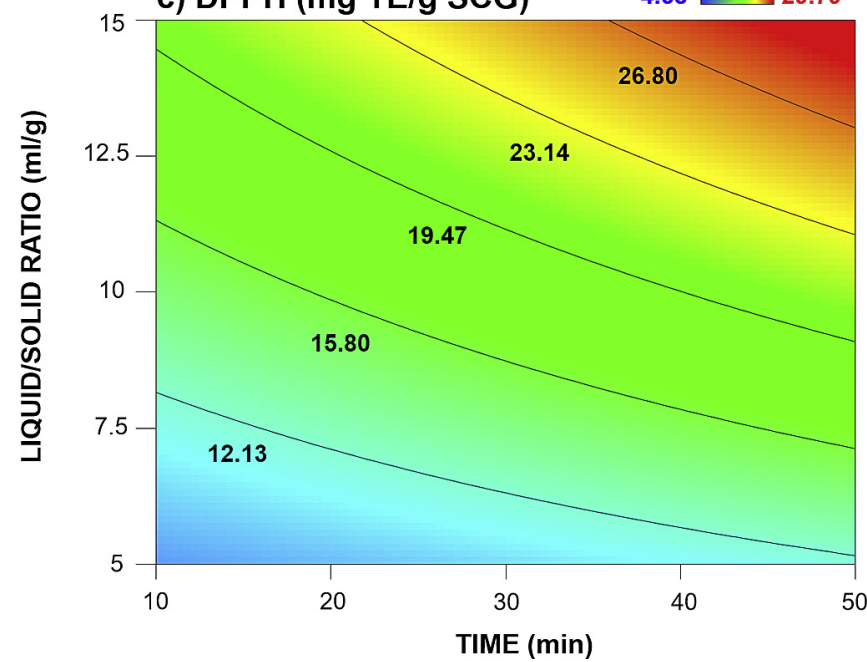

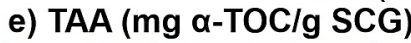

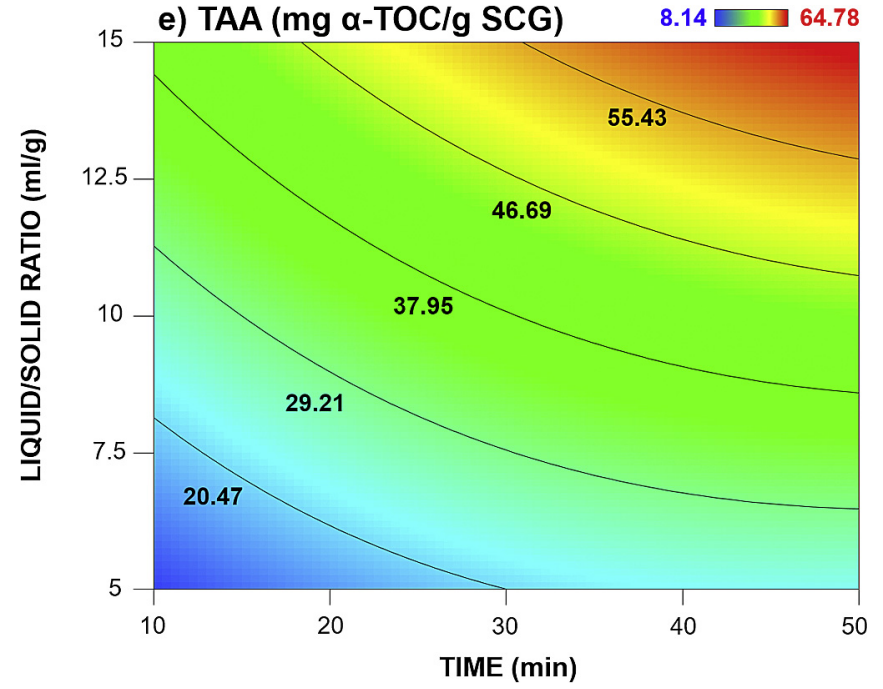

b) FRAP (mg Fe(II)/g SCG)

$8.34 \square 69.50$
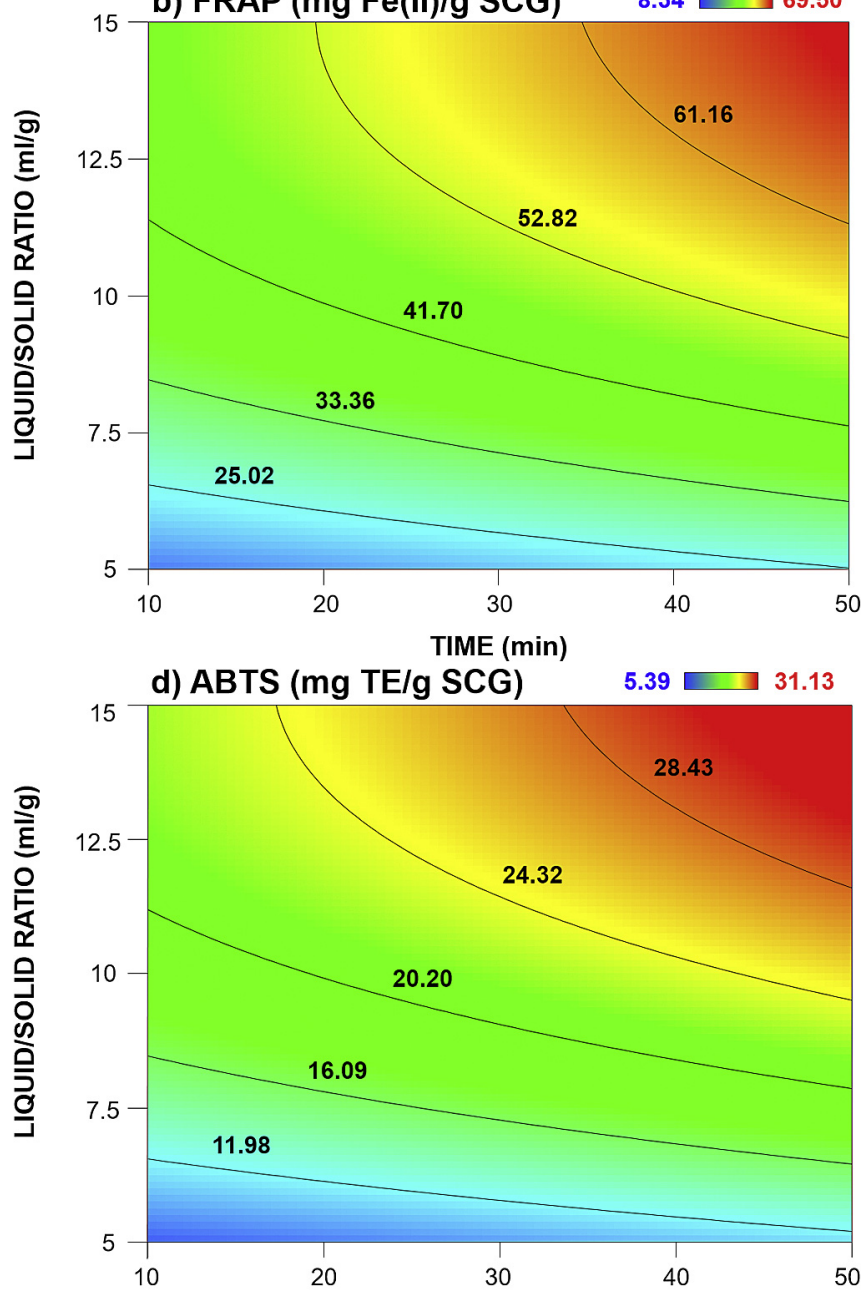

TIME (min)

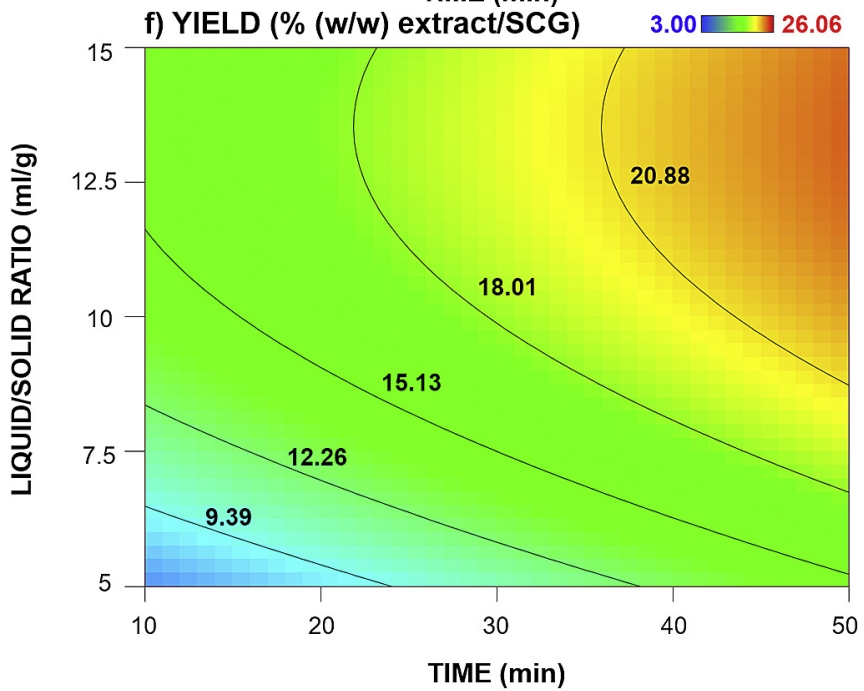

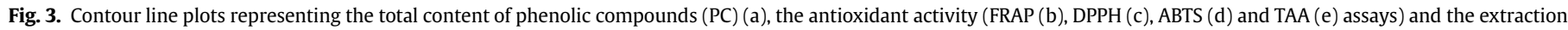
yield (f) of extracts obtained by autohydrolysis of spent coffee grounds under different conditions of extraction time and liquid/solid ratio, at a fixed temperature of $200{ }^{\circ} \mathrm{C}$.

reported by Panusa et al. (2013) also using ethanol as solvent (28.26 mg GAE/g SCG). Although organic solvents have been widely used to recover compounds from different natural sources, their toxic nature, mainly for isopropanol and methanol, cause serious issues for food and pharmaceutical applications. On the contrary, pure water, as used in the present study for autohydrolysis, is more 


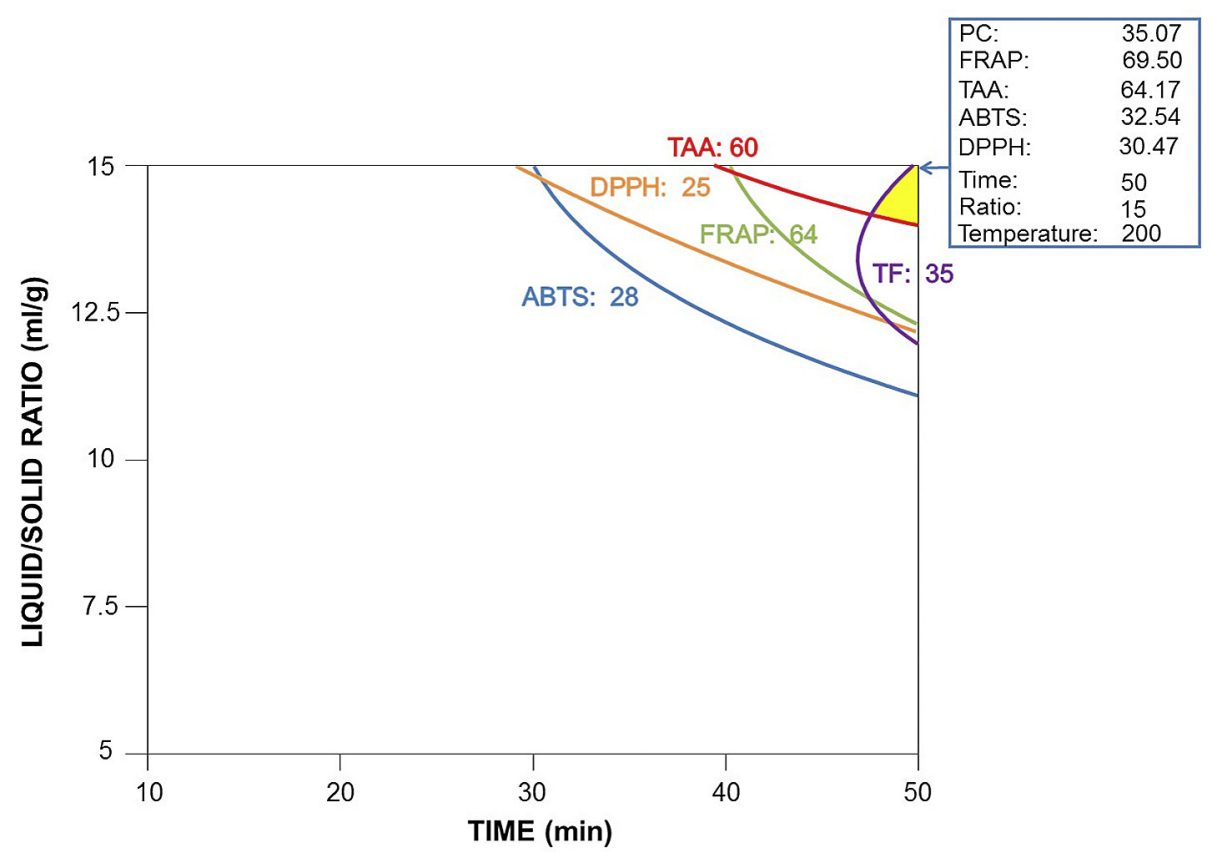

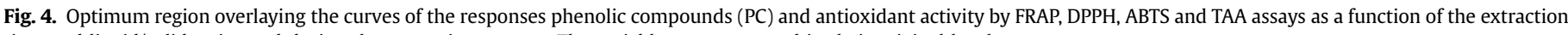
time and liquid/solid ratio used during the extraction process. The variables are presented in their original levels.

suitable to extract compounds for use in these type of applications, besides being able to extract a higher amount of antioxidant PC. It is also worth mentioning that the results of PC obtained in the present study under the optimized autohydrolysis conditions $\left(200^{\circ} \mathrm{C}\right.$, $15 \mathrm{ml}$ water/g SCG, $50 \mathrm{~min} ; 40.36 \mathrm{mg}$ GAE/g SCG) were 23\% higher than the values obtained by autohydrolysis under mild process conditions $\left(120^{\circ} \mathrm{C}, 20 \mathrm{ml}\right.$ water/g SCG, $20 \mathrm{~min} ; 32.92 \mathrm{mg} \mathrm{GAE} /$ g SCG) (Conde and Mussatto, 2016), confirming the importance of optimizing the process conditions in order to maximize the extraction results.

Finally, the extract produced under the optimized process conditions was submitted to HPLC and colorimetric analyses for characterization. As a result, flavonoids and chlorogenic acid were found in the extract in concentrations of $1.87 \pm 0.11$ (mg QE/g SCG) and $2.25 \pm 0.02(\mathrm{mg} / \mathrm{g} \mathrm{SCG})$, respectively. Sugar derived compounds including furfural and hydroxymethylfurfural were also identified in the extract in concentrations of $1.40 \pm 0.02$ and $2.09 \pm 0.04(\mathrm{mg} /$ g SCG), respectively. Flavonoids and chlorogenic acid, in particular, have antioxidant capacity and numerous bio-functionalities, which contribute positively to health and well-being (Middleton et al.,
2000; Shan et al., 2009; Mussatto, 2015). Flavonoids, for example, have been reported to prevent cardiovascular diseases, and to reduce the risk of Alzheimer and Parkinson diseases. Chlorogenic acid has a wide number of biological activities, including hypoglycemic, hepatoprotective, antiviral, antibacterial, anticarcinogenic, and anti-inflammatory activities, which are mostly related to its potent antioxidant activity. Therefore, chlorogenic acid has been considered as a promising candidate for use as a therapeutic agent (Mussatto, 2015). Such properties make possible the application of these compounds in different areas, including food, pharmaceuticals, and cosmetics. This fact opens up great opportunities for industrial application of the SCG extract produced in the present study under the optimized process conditions.

\section{Conclusion}

Autohydrolysis, which is an eco-friendly method that employs only water as extraction solvent, was an efficient technology to extract antioxidant phenolic compounds from spent coffee grounds. The total content of phenolic compounds and the

Table 3

Results obtained in the assays for validation of the conditions optimized for extraction of antioxidant phenolic compounds by autohydrolysis of spent coffee grounds.

\begin{tabular}{|c|c|c|c|c|c|c|c|c|}
\hline \multirow[t]{2}{*}{ Experimental assay } & \multicolumn{3}{|c|}{$\begin{array}{l}\text { Process variables optimum } \\
\text { point values }^{\mathrm{a}}\end{array}$} & \multicolumn{5}{|l|}{ Responses $^{\mathrm{b}}$} \\
\hline & $\mathrm{X}_{1}$ & $\mathrm{X}_{2}$ & $\mathrm{X}_{3}$ & PC & FRAP & DPPH & ABTS & TAA \\
\hline 1 & 200 & 15 & 50 & $40.43 \pm 1.00$ & $69.50 \pm 2.28$ & $28.06 \pm 0.25$ & $31.36 \pm 0.02$ & $66.95 \pm 0.35$ \\
\hline 2 & 200 & 15 & 50 & $41.23 \pm 0.79$ & $66.72 \pm 1.56$ & $27.79 \pm 0.04$ & $31.78 \pm 0.07$ & $63.40 \pm 0.38$ \\
\hline 3 & 200 & 15 & 50 & $39.36 \pm 2.13$ & $69.50 \pm 1.24$ & $28.60 \pm 0.08$ & $31.49 \pm 0.57$ & $68.27 \pm 0.38$ \\
\hline \multicolumn{4}{|l|}{ Average } & $40.36 \pm 0.90$ & $68.58 \pm 1.61$ & $28.15 \pm 0.41$ & $31.54 \pm 1.13$ & $66.21 \pm 2.51$ \\
\hline \multicolumn{4}{|l|}{ Criteria } & $\geq 35.00$ & $\geq 64.00$ & $\geq 25.00$ & $\geq 28.00$ & $\geq 60.00$ \\
\hline \multicolumn{4}{|c|}{ Results predicted by the statistical analysis } & 35.07 & 69.50 & 30.47 & 32.54 & 64.17 \\
\hline
\end{tabular}

${ }^{\text {a }} \mathrm{X}_{1}$ : temperature $\left({ }^{\circ} \mathrm{C}\right) ; \mathrm{X}_{2}$ : liquid/solid ratio $(\mathrm{ml} / \mathrm{g}) ; \mathrm{X}_{3}$ : extraction time (min).

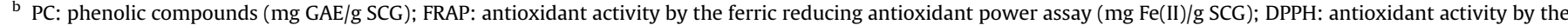

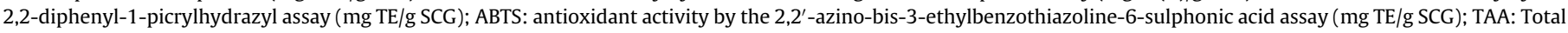
antioxidant activity ( $\mathrm{mg} \alpha$-TOC/g SCG). 
antioxidant activity of the produced extract were affected by the variables used in the process, the liquid/solid ratio being the process variable with the highest influence on all the responses. The optimal extraction condition, achieved when using a temperature of $200^{\circ} \mathrm{C}$, liquid/solid ratio of $15 \mathrm{ml} / \mathrm{g}$ and extraction time of $50 \mathrm{~min}$, was able to produce an extract containing high content of phenolic compounds (40.36 mg GAE/g SCG), including flavonoids and chlorogenic acid, and high antioxidant activity (FRAP $=69.50 \mathrm{mg}$ $\mathrm{Fe}(\mathrm{II}) / \mathrm{g}$ SCG, DPPH $=28.25 \mathrm{mg}$ TE $/ \mathrm{g}$ SCG, ABTS $=31.46 \mathrm{mg} \mathrm{TE} / \mathrm{g}$ SCG and TAA $=66.21 \mathrm{mg} \alpha-\mathrm{TOC} / \mathrm{g} \mathrm{SCG}$ ). Such results highlight the great potential of spent coffee grounds for use as raw material on biotechnological processes due to their antioxidant capacity and presence of phenolic compounds, which have an outstanding role in health area, and wide applications in food and pharmaceutical products.

\section{Acknowledgements}

This work was supported by the Science and Technology Foundation of Portugal (FCT - grant SFRH/BD/80948/2011); the Strategic Project PEst-OE/EQB/LA0023/2013; and the Project "BioInd -Biotechnology and Bioengineering for improved Industrial and Agro-Food processes", REF. NORTE-07-0124-FEDER-000028 cofunded by the Programa Operacional Regional do Norte (ON.2 O Novo Norte), QREN, FEDER.

\section{References}

Alothman, M., Bhat, R., Karim, A., 2009. Antioxidant capacity and phenolic content of selected tropical fruits from Malaysia, extracted with different solvents. Food Chem. 115, 785-788.

Ballesteros, L.F., Cerqueira, M.A., Teixeira, J.A., Mussatto, S.I., 2015. Characterization of polysaccharides extracted from spent coffee grounds by alkali pretreatment. Carbohydr. Polym. 127, 347-354.

Ballesteros, L.F., Teixeira, J.A., Mussatto, S.I., 2014a. Chemical, functional, and structural properties of spent coffee grounds and coffee silverskin. Food Bioprocess Technol. 7, 3493-3503.

Ballesteros, L.F., Teixeira, J.A., Mussatto, S.I., 2014b. Selection of the solvent and extraction conditions for maximum recovery of antioxidant phenolic compounds from coffee silverskin. Food Bioprocess Technol. 7, 1322-1332.

Cai, Y., Luo, Q., Sun, M., Corke, H., 2004. Antioxidant activity and phenolic compounds of 112 traditional Chinese medicinal plants associated with anticancer. Life Sci. 74, 2157-2184.

Carvalheiro, F., Esteves, M., Parajó, J., Pereira, H., Girio, F., 2004. Production of oligosaccharides by autohydrolysis of brewery's spent grain. Bioresour. Technol. 91, 93-100.

Conde, E., Moure, A., Domínguez, H., Parajó, J.C., 2011. Production of antioxidants by non-isothermal autohydrolysis of lignocellulosic wastes. LWT-Food Sci. Technol. 44, 436-442.

Conde, T., Mussatto, S.I., 2016. Isolation of polyphenols from spent coffee grounds and silverskin by mild hydrothermal pretreatment. Prep. Biochem. Biotechnol. http://dx.doi.org/10.1080/10826068.2015.1084514.

Cortazar, E., Bartolomé, L., Delgado, A., Etxebarria, N., Fernández, L., Usobiaga, A.,
Zuloaga, O., 2005. Optimisation of microwave-assisted extraction for the determination of nonylphenols and phthalate esters in sediment samples and comparison with pressurised solvent extraction. Anal. Chim. Acta 534, $247-254$.

Dorta, E., Lobo, M.G., Gonzalez, M., 2012. Reutilization of mango byproducts: study of the effect of extraction solvent and temperature on their antioxidant properties. J. Food Sci. 77, C80-C88.

Farah, A., Donangelo, C.M., 2006. Phenolic compounds in coffee. Braz. J. Plant Physiol. 18, 23-36.

Jiménez, J.P., Serrano, J., Tabernero, M., Arranz, S., Díaz-Rubio, M.E., García-Diz, L., ... Saura-Calixto, F., 2008. Effects of grape antioxidant dietary fiber in cardiovascular disease risk factors. Nutrition 24, 646-653.

Karadag, A., Ozcelik, B., Saner, S., 2009. Review of methods to determine antioxidant capacities. Food Anal. Methods 2, 41-60.

Katritzky, A.R., Allin, S.M., 1996. Aquathermolysis: reaction of organic compounds with superheated water. Acc. Chem. Res. 29, 399-406.

Markom, M., Hasan, M., Daud, W.R.W., Singh, H., Jahim, J.M., 2007. Extraction of hydrolysable tannins from Phyllanthus niruri Linn.: effects of solvents and extraction methods. Sep. Purif. Technol. 52, 487-496.

Martins, S., Mussatto, S.I., Martínez-Avila, G., Montañez-Saenz, J., Aguilar, C.N., Teixeira, J.A., 2011. Bioactive phenolic compounds: production and extraction by solid-state fermentation. A review. Biotechnol. Adv. 29, 365-373.

Middleton, E., Kandaswami, C., Theoharides, T.C., 2000. The effects of plant flavonoids on mammalian cells: implications for inflammation, heart disease, and cancer. Pharmacol. Rev. 52, 673-751.

Murthy, P.S., Naidu, M.M., 2012. Recovery of phenolic antioxidants and functional compounds from coffee industry by-products. Food Bioprocess Technol. 5, 897-903.

Mussatto, S.I., Ballesteros, L.F., Martins, S., Teixeira, J.A., 2011b. Extraction of antioxidant phenolic compounds from spent coffee grounds. Sep. Purif. Technol. 83, $173-179$.

Mussatto, S.I., Machado, E.M., Martins, S., Teixeira, J.A., 2011a. Production, composition, and application of coffee and its industrial residues. Food Bioprocess Technol. 4, 661-672.

Mussatto, S.I., 2015. Generating biomedical polyphenolic compounds from spent coffee or silverskin. In: Preedy, V.R. (Ed.), Coffee in Health and Disease Prevention. Elsevier, London, pp. 93-106.

Nabarlatz, D., Ebringerová, A., Montané, D., 2007. Autohydrolysis of agricultural byproducts for the production of xylo-oligosaccharides. Carbohydr. Polym. 69, $20-28$.

Panusa, A., Zuorro, A., Lavecchia, R., Marrosu, G., Petrucci, R., 2013. Recovery of natural antioxidants from spent coffee grounds. J. Agric. Food Chem. 61, 4162-4168.

Prasad, K.N., Yang, E., Yi, C., Zhao, M., Jiang, Y., 2009. Effects of high pressure extraction on the extraction yield, total phenolic content and antioxidant activity of longan fruit pericarp. Innov. Food Sci. Emerg. Technol. 10, 155-159.

Prasad, K.N., Hassan, F.A., Yang, B., Kong, K.W., Ramanan, R.N., Azlan, A., Ismail, A 2011. Response surface optimisation for the extraction of phenolic compounds and antioxidant capacities of underutilised Mangifera pajang Kosterm. peels. Food Chem. 128, 1121-1127.

Rodríguez-Meizoso, I., Jaime, L., Santoyo, S., Señoráns, F.J., Cifuentes, A., Ibáñez, E. 2010. Subcritical water extraction and characterization of bioactive compounds from Haematococcus pluvialis microalga. J. Pharm. Biomed. Anal. 51, 456-463.

Shan, J., Fu, J., Zhao, Z., Kong, X., Huang, H., Luo, L., Yin, Z., 2009. Chlorogenic acic inhibits lipopolysaccharide-induced cyclooxygenase-2 expression in RAW264. 7 cells through suppressing $\mathrm{NF}-\kappa \mathrm{B}$ and JNK/AP-1 activation. Int. Immunopharmacol. 9, 1042-1048.

Stratil, P., Klejdus, B., Kubáň, V., 2007. Determination of phenolic compounds and their antioxidant activity in fruits and cereals. Talanta 71, 1741-1751.

Zuorro, A., Lavecchia, R., 2012. Spent coffee grounds as a valuable source of phenolic compounds and bioenergy. J. Clean. Prod. 34, 49-56. 